\title{
АРТЕРИИТ ТАКАЯСУ: РЕЗУЛЬТАТЫ РЕТРОСПЕКТИВНОГО АНАЛИЗА ПАЦИЕНТОВ УРАЛЬСКОЙ ПОПУЛЯЦИИ
}

\author{
И. Э. Бородина ${ }^{1,2}$, А. А. Попов², Г. Г. Салаватова ${ }^{1}$, Л. А. Шардина ${ }^{2}$ \\ 1 Свердловская областная клиническая больница № 1, Екатеринбург, Россия \\ 2 Уральский государственный медицинский университет, Екатеринбург, Россия
}

\begin{abstract}
Артериит Такаясу (АТ) - редкое заболевание, которое ревматологи, врачи общей практики и другие специалисты могут не распознать при первичном посещении пациента из-за различных клинических проявлений. Целью исследования было оценить клиническую картину и течение АТ у 183 пациентов Среднего Урала. В ретроспективную часть исследования вошли 183 страдающих АТ пациентов, наблюдавшиеся в Свердловской областной клинической больнице № 1 в период с 1979 по 2018 г. Соотношение мужчин и женщин составляло 1 : 3. Средний возраст женщин - 33,5 года, мужчин - 35,2 лет. Наиболее часто были зарегистрированы поражения следующих артерий: подключичной — 101 (55\%) случай, сонной — 98 (53\%) случаев и почечных 77 (42\%) случаев. Наиболее часто встречался ангиографический тип V, а типичным ангиографическим признаком был артериальный стеноз - 94 (51\%), Хирургические вмешательства выполнены 66 пациентам. За период исследования зарегистрирован 31 летальный исход, пятилетняя выживаемость составила 92\%; 10-летняя — 90\%, а 15-летняя - 80\%. У 72 (39\%) пациентов развились клинически значимые сердечно-сосудистые события: инфаркт миокарда, ишемический инсульт, тромбоз крупной артерии и венозный тромбоз. В разных географических зонах АТ может иметь широкий спектр клинических проявлений
\end{abstract}

Ключевые слова: артериит Такаясу, клинические проявления, почечная артерия

Информация о вкладе авторов: все авторы принимали участие в планировании работы, статистической обработке, обсуждении результатов, написании и редактировании текста. И. Э. Бородина и Г. Г. Салаватова проводили сбор первичного материала и формирование электронной базы данных.

Соблюдение этических стандартов: исследование одобрено этическим комитетом ФБГОУ ВО УГМУ Министерства здравоохранения России, протокол № 9 от 23 ноября 2018 г.

Для корреспонденции: Ирина Эдуардовна Бородина

ул. Репина, д. 3, г. Екатеринбург, Свердловская обл., 620014; borodysik@mail.ru

Статья получена: 10.08.2018 Статья принята к печати: 02.03.2019 Опубликована онлайн: 14.03.2019

DOI: $10.24075 /$ vrgmu.2019.012

\section{TAKAYASU'S ARTERITIS: THE RETROSPECTIVE ANALYSIS OF PATIENTS FROM THE URAL POPULATION}

Borodina IE ${ }^{1,2}$, Popov AA², Salavatova GG ${ }^{1}$, Shardina LA²

${ }_{1}^{1}$ Sverdlovsk Regional Clinical Hospital No.1, Yekaterinburg, Russia

2 Ural State Medical University, Yekaterinburg, Russia

Takayasu's arteritis (TA) is a rare disease that can be overlooked during the first visit to a GP, rheumatologist, or any other medical specialist due to a variety of its symptoms. The aim of this study was to describe the clinical presentation and the course of patients with TA residing in the Middle Ural. A retrospective analysis was conducted using the medical records of 183 patients treated at the Sverdlovsk Regional Clinical Hospital 1 from 1979 through 2018 . The male to female ratio was 1:3. The mean age was 33.5 years for women and 35.2 for men. The most frequently involved arteries were subclavian (101 cases; $55 \%$ ), carotid (98 cases; 53\%) and renal (77 cases; 42\%). Type $\vee$ was the most common angiographic type. Arterial stenosis was present in 94 (51\%) patients. Sixty-six patients received surgical interventions. Of all patients included in the analysis, 31 died. The observed 5-year survival was 92\%, 10-year survival, 90\% and 15-year survival, 80\%. Seventy-two patients (39\%) developed major adverse cardiovascular events (MACE), including myocardial infarction, ischemic stroke, and thrombosis of large arteries/veins. The clinical presentation of TA may vary in different geographical regions.

Keywords: Takayasu's arteritis, clinical symptoms, renal artery

Author contribution: all authors participated in conceiving and planning the study, processing the data, discussing the results, and writing the manuscript. Borodina IE and Salavatova GG collected the medical records for the electronic database.

Compliance with ethical standards: the study was approved by the Ethics Committee of Ural State Medical University (Protocol No. 9 dated November 23, 2018).

Correspondence should be addressed: Irina E. Borodina

Repina 3, Yekaterinburg, Sverdlovsk region, 620014; borodysik@mail.ru

Received: 10.08.2018 Accepted: 02.03.2019 Published online: 14.03.2019

DOI: 10.24075/brsmu.2019.012

Артериит Такаясу (АТ) представляет собой гранулематозное воспаление аорты и ее крупных ветвей. Считается, что AT встречается в основном в Азии и Южной Америке, но нечастые случаи регистрируются и в других частях мира [1]. Распространенность АТ варьирует от 0,8 до 2,6 случаев на 1000 000, в зависимости от региона проживания и этнической группы [2]. В Российской Федерации отсутствуют эпидемиологические данные для оценки распространенности АТ. Между тем, из-за несвоевременной диагностики начало лечения может быть отсрочено, что может привести к серьезным неблагоприятным сердечно-сосудистым событиям (MACE) и преждевременной смерти, которые можно предотвратить.

Клиническое начало АТ может имитировать широкий спектр заболеваний без классических признаков и симптомов, таких как асимметрия пульса или артериального давления на верхних конечностях, но с выраженной артериальной гипертензией, ухудшением зрения или болью в животе.

Целью исследования было ретроспективно описать клинические проявления лабораторных и рентгенологических 
особенностей, течения и исходов АТ у 183 больных, проживающих на территории Среднего Урала.

\section{ПАЦИЕНТЫ И МЕТОДЫ}

В ретроспективное когортное исследование включены 183 пациента с верифицированным АТ, наблюдавшихся в Свердловской областной клинической больнице (ОКБ) № 1 в период с 1979 по 2018 г. Среди пациентов были: 139 женщин в возрасте на момент установления заболевания от 9 до 62 лет (средний возраст - 33,5; медиана - 35; 25\%-75\% - 24-43) и 44 мужчины в возрасте от 12 до 59 лет (средний возраст - 35,18; медиана - 34; 25\%-75\% 26,5-42). Длительность заболевания у женщин от 0,6 до 64 лет (в среднем 12,3 года; медиана составила 10 лет (25\%-75\% - 4-18), у мужчин - от 0,6 до 32 лет (в среднем 9 лет; медиана у мужчин - 7 лет (25\%-75\% - 4-14,5). Длительность от первых симптомов до постановки диагноза у женщин составляла 0,6-54 года (в среднем 5,7 лет; медиана - 3 года; 25\%-75\% - 1-7), у мужчин 0,6-33 года (в среднем 6 лет; медиана - 4 года; 25\%-75\% - 1,5-8) (табл. 1).

Первичный диагноз АТ при анализе медицинских карт верифицировали в соответствии с критериями Американской коллегии ревматологов 1990 г. [3].

По унифицированному протоколу собирали и анализировали демографические данные, клинические и ангиографические особенности и связанные с АТ хирургические вмешательства, результаты лабораторных исследований. Характеристику поражения артерий по данным ангиографии проводили по критериям Moriwaki [4]. Для оценки степени поражения сосудов использовали данные контрастной ангиографии и/или компьютерной томограсии (KT), и/или МРТ-ангиографии, и/или УЗДГ артерий. Различие методов визуализации артерий для оценки локализации и распространенности изменений (стеноз, окклюзия, дилатация, диссекция и др.) было

Таблица 1. Общая характеристика пациентов, страдающих артериитом Такаясу, включенных в ретроспективное исследование

\begin{tabular}{|c|c|c|c|}
\hline \multirow{2}{*}{ Характеристики } & \multicolumn{3}{|c|}{ Пациенты когорты } \\
\hline & $\begin{array}{l}\text { Женщины } \\
139 \text { (76\%) }\end{array}$ & $\begin{array}{c}\text { Мужчины } \\
44 \text { (24\%) }\end{array}$ & $\begin{array}{c}\text { Всего } \\
n=183(100 \%)\end{array}$ \\
\hline Возраст на момент установления заболевания, лет, Ме [25\%-75\%] & 35 [24-43] & $34[26,5-42]$ & 35 [24-43] \\
\hline Длительность заболевания, годы, Ме [25\%-75\%] & $10[4-18]$ & $7[4-14,5]$ & $13,5[6-20]$ \\
\hline Длительность от первых симптомов до постановки диагноза, годы, Ме [25\%-75\%] & $3[1-7]$ & $4[1,5-8]$ & $3[1-8]$ \\
\hline
\end{tabular}

Таблица 2. Клинические и лабораторные данные пациентов на момент исследования

\begin{tabular}{|c|c|}
\hline & Пациенты $(n=183)$ \\
\hline Артериальная гипертензия & $98(53 \%)$ \\
\hline Боль, слабость, онемение, асимметрия пульса на верхних конечностях & $89(49 \%)$ \\
\hline Общая слабость & $87(47,5 \%)$ \\
\hline Головные боли & $86(47 \%)$ \\
\hline Лихорадка & $65(35,5 \%)$ \\
\hline Снижение веса & $44(24 \%)$ \\
\hline Перемежающаяся хромота & $40(22 \%)$ \\
\hline Головокружение & $40(2 \%)$ \\
\hline Разность артериального давления на верхних конечностях более 10 мм рт. ст. & $37(20 \%)$ \\
\hline Хроническая абдоминальная ишемия & $36(20 \%)$ \\
\hline Боли в груди & $31(17 \%)$ \\
\hline Боль, слабость, онемение нижних конечностей & $26(14 \%)$ \\
\hline Одышка & $16(8 \%)$ \\
\hline Артралгии & $13(7 \%)$ \\
\hline \multicolumn{2}{|l|}{ Лабораторные данные } \\
\hline СОЭ (мм/ч), Me [25\%-75\%] & 18 [6-28] \\
\hline СРБ (г/л), Me [25\%-75\%] & $0,3[0-6]$ \\
\hline Лейкоциты (10\%/л), Ме [25\%-75\%] & $6,2[4-8,7]$ \\
\hline Гемоглобин (г/л), Ме [25\%-75\%] & 119 [97-128] \\
\hline \multicolumn{2}{|l|}{ Тип АТ по } \\
\hline 1 & $60(33 \%)$ \\
\hline $2 a$ & $9(5 \%)$ \\
\hline $2 b$ & $1(0,5 \%)$ \\
\hline 3 & $3(2 \%)$ \\
\hline 4 & $32(17 \%)$ \\
\hline 5 & $78(43 \%)$ \\
\hline
\end{tabular}

Примечание: Ме - медиана; 25\% — нижний квартиль; 75\% - верхний квартиль. 
обусловлено ретроспективным характером исследования и изменением технического обеспечения и клинической практики, произошедшим в течение периода наблюдения. Однако у каждого пациента данные оценки с помощью УЗДГ были подтверждены, как минимум, одним обследованием с применением контрастирования сосудов.

Описание клинических и ангиографических проявлений болезни у других этнических групп получали в результате поиска в базе данных PubMed с помощью ключевых слов «Takayasu's arteritis». Критерии включения для пациентов в этих работах также основаны на рекомендациях ACR 1990 г. и соответствуют критериям, использованным нами [3]: АТ, диагностированный при наличии трех и более следующих симптомов (чувствительность 90\%, специфичность 97,8\%): возраст начала заболевания до 40 лет, синдром перемежающейся хромоты (слабость и боли в мышцах конечностей при движениях), ослабление пульса на одной или обеих плечевых артериях, разница в показателях уровня артериального давления более 10 мм рт. ст. на плечевых артериях, шум на подключичных артериях или брюшной аорте, изменения при ангиограсии (сужение просвета или окклюзия аорты, ее крупных ветвей в проксимальных отделах верхних и нижних конечностей, не связанные с атеросклерозом, фибромускулярной дисплазией, спазмом).

Полученные результаты сопоставляли со справочными данными Elibrary (бесплатный полнотекстовый архив литературы по биомедицинским и естественным наукам на русском языке), использовали ключевые слова «артериит Такаясу» и АТ для получения клинических и ангиографических проявлений заболевания в случаях, зарегистрированных в России $[1,14,19,20]$.

\section{Статистический анализ}

Для статистической обработки данных использовали лицензионный программный продукт Statistica 7.0 (Statsoft inc., США). Категориальные переменные анализировали с помощью критерия хи-квадрат. Все статистические тесты были двусторонними и статистически значимыми ( $<$ 0,05). Для оценки ряда признаков, влияющих на выживаемость пациентов, страдающих АТ, использовали анализ выживаемости по Каплану-Майеру. Различия между группами оценивали методом логарифмического ранжирования.

\section{РЕЗУЛЬТАТЫ}

\section{Демографические данные и клинические проявления}

На момент обследования наиболее частыми клиническими проявлениями были общая слабость (47,5\%), артериальная гипертензия (53\%), асимметрия пульса на верхних конечностях (49\%), боль, снижение силы, онемение верхних конечностей (49\%), головная боль (47\%) (табл. 2).

Скорость оседания эритроцитов (СОЭ), уровни С-реактивного белка (СРБ) и высокочувствительного СРБ были повышены (табл. 2). Наиболее частым поражением сосудов было вовлечение дуги аорты, ее основных ветвей, а также поражения брюшной аорты и / или почечных артерий (тип V).

Наиболее часто отмечали вовлечение в патологический процесс подключичной, сонной и почечной артерий. Наиболее типичным видом поражения артерий был стеноз (табл. 3).
Оперативное лечение было проведено 66 (36\%) пациентам (23 мужчинам и 43 женщинам). Показаниями к хирургическим вмешательствам были: гемодинамически значимые стенозы, окклюзии и тромбозы пораженных сосудов; артериальная гипертензия, обусловленная стенозом почечных артерий или субтотальным стенозом аорты, наличие симптомов ишемии верхних или нижних конечностей в стадии декомпенсации. Оперативное лечение при аортоартериите можно разделить на две группы: эндоваскулярное (стентирование, протезирование, ангиопластика) и реконструктивные оперативные вмешательства. Кроме того, в одном случае в связи с наличием аневризмы и тромбоза почечных артерий и последующим несросклерозом была проведена несрэктомия и аутотрансплантация почки (табл. 4).

В консервативной терапии превалировали монотерапия глюкокортикоидами - 96 (52\%) и использование дезагрегантов (аспирин, дипиридамол) - 116 (63\%) (табл. 5).

С 1979 по 2018 г. был зафиксирован 31 случай смерти пациентов с АТ (18 мужчин / 13 женщин). Обращает на себя внимание молодой возраст умерших: средний возраст смерти у женщин - 38 лет (Ме [25\%-75\%] - 36 [32-44]) и 49 лет у мужчин (Ме [25\%-75\%] - 50 [40-57]). Средняя продолжительность болезни к моменту смерти с момента установления диагноза составила 9,25 года (6,5 [3-16]) у мужчин и 9 лет (5 [3-10]) у женщин. Данные о причинах смерти были получены из протоколов аутопсий $(n=22)$ и по результатам опроса близких родственников пациентов ( $n=9)$ (табл. 6).

Таблица 3. Характеристика поражения артерий при AT

\begin{tabular}{|c|c|}
\hline Вовлеченные артерии & $n$ \\
\hline Подключичные & $101(55 \%)$ \\
\hline Сонные & $98(53 \%)$ \\
\hline Позвоночная & $16(9 \%)$ \\
\hline Подмышечная & $11(6 \%)$ \\
\hline Плечевая & $12(6,5 \%)$ \\
\hline Легочные & $6(3 \%)$ \\
\hline Коронарные & $31(17 \%)$ \\
\hline Чревный ствол & $42(23 \%)$ \\
\hline Верхняя брыжеечная артерия & $45(25 \%)$ \\
\hline Почечные & $77(42 \%)$ \\
\hline Бедренные & $25(14 \%)$ \\
\hline Подвздошные & $33(18 \%)$ \\
\hline Дуга аорты & $39(21 \%)$ \\
\hline Восходящий отдел грудной аорты & $15(8 \%)$ \\
\hline Нисходящий отдел грудной аорты & $9(5 \%)$ \\
\hline Брюшной отдел аорты & $52(28,4 \%)$ \\
\hline Типы поражения артерий & $n$ \\
\hline Стеноз & $94(51 \%)$ \\
\hline Стеноз + окклюзия & $55(30 \%)$ \\
\hline Окклюзия / аневризма & $2(1 \%)$ \\
\hline Стеноз / аневризма / окклюзия & $7(4 \%)$ \\
\hline Окклюзия & $8(4 \%)$ \\
\hline Стеноз + коарктация & $3(2 \%)$ \\
\hline Стеноз + аневризма & $14(7,6 \%)$ \\
\hline
\end{tabular}


Таблица 4. Объем хирургических вмешательств при АТ

\begin{tabular}{|c|c|}
\hline Оперативное вмешательство & Пациенты $(n=66)$ \\
\hline Протезирование аутовеной почечной артерии & $4(6 \%)$ \\
\hline Сонно-подключичное шунтирование & $4(6 \%)$ \\
\hline Аутовенозное протезирование плечевой артерии & $1(1,5 \%)$ \\
\hline Аутовенозная пластика плечевой артерии & $1(1,5 \%)$ \\
\hline Стентирование почечной артерии & $13(20 \%)$ \\
\hline Десцендобифеморальное шунтирование & $3(4,5 \%)$ \\
\hline Торакоабдоминальное шунтирование & $2(3 \%)$ \\
\hline Протезирование чревного ствола, верхней брыжеечной артерии & $3(4,5 \%)$ \\
\hline Тромбэктомия из брюшной аорты & $2(3 \%)$ \\
\hline АББШ & $7(11 \%)$ \\
\hline Ангиопластика почечной артерии & $11(17 \%)$ \\
\hline Стентирование общей сонной артерии & $1(1,5 \%)$ \\
\hline Ангиопластика подключичной артерии & $1(1,5 \%)$ \\
\hline Стентирование подключичной артерии & $1(1,5 \%)$ \\
\hline Тромбэктомия из протезо-подколенного шунта & $1(1,5 \%)$ \\
\hline $\begin{array}{l}\text { АББШ + протезирование ПБА справа. Тромбоз АББ протеза / Тромбэктомия из обеих браншей АББ протеза. } \\
\text { Пластика ПБА, ГБА слева с формированием единого устья, протезная профундопластика справа }\end{array}$ & $1(1,5 \%)$ \\
\hline Дилатация правой почечной артерии & $2(3 \%)$ \\
\hline Аутотрансплантация почки & $1(1,5 \%)$ \\
\hline Нефрэктомия & $4(6 \%)$ \\
\hline Тромбэктомия почечной артерии & $2(3 \%)$ \\
\hline Протезирование БЦА & $2(3 \%)$ \\
\hline Эндартерэктомия левой почечной артерии & $1(1,5 \%)$ \\
\hline Подключично-сонный анастомоз & $2(3 \%)$ \\
\hline Эндартерэктомия из чревного ствола & $1(1,5 \%)$ \\
\hline Тромбэктомия из плечевой артерии & $1(1,5 \%)$ \\
\hline Тромбэктомия из ПБА справа & $1(1,5 \%)$ \\
\hline Тромбэктомия из правой бранши протеза & $1(1,5 \%)$ \\
\hline Ампутация бедра & $2(3 \%)$ \\
\hline Ревизия брюшной полости по поводу мезентериального тромбоза & $1(1,5 \%)$ \\
\hline Протезирование инфраренального отдела аорты & $1(1,5 \%)$ \\
\hline Резекция тонкой кишки с анастомозом конец в конец по поводу острого мезентериального тромбоза & $1(1,5 \%)$ \\
\hline Резекция аневризмы брахиоцефального ствола & $2(3 \%)$ \\
\hline Бифуркационное аорто-сонно-брахиоцефальное аллопротезирование & $3(4,5 \%)$ \\
\hline Тромбэктомия из общей сонной артерии & $2(3 \%)$ \\
\hline Резивия брюшной полости, почечных артерий & $2(3 \%)$ \\
\hline $\begin{array}{l}\text { Резекция правой половины толстой кишки и терминального отдела подвздошной кишки } \\
\text { с наложением еюнотрансверзоанастомоза по поводу острого мезентериального тромбоза }\end{array}$ & $1(1,5 \%)$ \\
\hline Тромбэктомия из подвздошно-бедренного сегмента & $1(1,5 \%)$ \\
\hline Имплантация артериовенозного шунта левого предплечья & $1(1,5 \%)$ \\
\hline Аортобикаротидное шунтирование & $3(4,5 \%)$ \\
\hline Торакоабдоминальное протезирование по поводу коартации аорты & $1(1,5 \%)$ \\
\hline Резекция аневризмы брюшного отдела аорты & $1(1,5 \%)$ \\
\hline Стентирование аорты по поводу коарктации & $1(1,5 \%)$ \\
\hline Резекция аневризмы проксимального анастомоза (подключичной артерии) & $1(1,5 \%)$ \\
\hline Сонно-подключичное протезирование & $1(1,5 \%)$ \\
\hline Аутовенозная пластика подключично-мышечного сегмента & $1(1,5 \%)$ \\
\hline Дилатация плечевой артерии & $1(1,5 \%)$ \\
\hline Подвздошно-бедренное шунтирование & $1(1,5 \%)$ \\
\hline Стентирование коронарных артерий & $5(7,5 \%)$ \\
\hline АМКШ & $1(1,5 \%)$ \\
\hline Стентирование ГБА слева & $1(1,5 \%)$ \\
\hline Линейное подвздошно-бедренное шунтирование слева & $1(1,5 \%)$ \\
\hline
\end{tabular}

Примечание: АББШ - аортобедренное шунтирование; АМКШ - аорто- и маммарокоронарное шунтирование; БЦА - брахиоцесальные артерии; ПБА — поверхностная бедренная артерия; ГБА — глубокая бедренная артерия. 
Определенный интерес представляет анализ выживаемости больных АТ (рис. 1). Пятилетняя выживаемость составила 92\%; 10-летняя - 90\%; 15-летняя - 80\% (медиана составила 34 [20-41]).

Всего было зафиксировано 72 сердечно-сосудистых исхода (27 мужчин и 45 женщин). Возраст дебюта заболевания: Мe [25\%-75\%] - 33 [26-43]. Длительность заболевания до развития события: Ме [25\%-75\%] 10 [5-20]. Возраст на момент сосудистых осложнений (МАCE) - 38 [30-49,5] (табл. 7).

\section{ОБСУЖДЕНИЕ}

Артериит Такаясу - считающееся редким заболевание изучают во всем мире в связи с высокой социальной и экономической значимостью, обусловленной серьезными сердечно-сосудистыми осложнениями, приводящими $\mathrm{k}$ инвалидности и преждевременной смерти молодых людей.

Несмотря на доступность диагностических возможностей, широкий спектр клинических проявлений, низкий уровень знаний врачей общей практики и органов общественного

Таблица 5. Медикаментозное лечение артериита Такаясу

\begin{tabular}{|l|c|}
\hline \multicolumn{1}{|c|}{ Вид лекарственной терапии } & Пациенты ( $n=183)$ \\
\hline Монотерапия глюкокортикоидами & 96 (52\%) \\
\hline ГКС + цитостатики (циклофосфамид, азатиоприн, гидроксихлорохин или метотрексат) & 43 (23\%) \\
\hline Без иммуносупрессивной терапии / или в документации нет данных о полном объеме проводимой терапии & 40 (21\%) \\
\hline Генноинженерные биологические препараты & 0 (0\%) \\
\hline Дезагреганты & 116 (63\%) \\
\hline Статины & 27 (15\%) \\
\hline Нестероидные противовоспалительные препараты & 42 (23\%) \\
\hline Плазмаферез & 31 (17\%) \\
\hline
\end{tabular}

Таблица 6. Причины смерти у пациентов с АT

\begin{tabular}{|c|c|}
\hline Причины смерти & Пациенты $(n=31)$ \\
\hline Множественные инфаркты головного мозга вследствие прогрессирующей ишемии головного мозга & $1(3 \%)$ \\
\hline Инфаркт головного мозга вследствие тромбоза внутренней сонной артерии & $1(3 \%)$ \\
\hline Крупноочаговая бронхопневмония & $1(3 \%)$ \\
\hline Сердечная декомпенсация вследствие недостаточности аортального клапана с формированием аортального порока & $2(6 \%)$ \\
\hline $\begin{array}{l}\text { Массивная кровопотеря вследствие несостоятельности швов сосудистого анастомоза } \\
\text { после аутовенозного протезирования почечной артерии }\end{array}$ & $1(3 \%)$ \\
\hline $\begin{array}{l}\text { Абсцедирующая бронхопневмония после аортобикаротидного протезирования, имплантация ЭКС } \\
\text { в миокардиальную позицию с последующим реперфузионным повреждением головного мозга }\end{array}$ & $1(3 \%)$ \\
\hline $\begin{array}{l}\text { Инфаркт головного мозга + энцефалопатия после реперфузионного повреждения головного мозга с послеоперационной } \\
\text { мозговой комой после аортобикаротидного протезирования }\end{array}$ & $1(3 \%)$ \\
\hline Послеоперационный сепсис вследствие гнойного медиастинита после формирования подключично-каротидного анастомоза & $1(3 \%)$ \\
\hline Инфаркт головного мозга вследствие тромбоэмболии после резекции аневризмы брахиоцефального сегмента & $1(3 \%)$ \\
\hline $\begin{array}{l}\text { Инфаркты головного мозга на фоне прогрессирующей ишемии головного мозга } \\
\text { после бифуркационного аорто-каротидного шунтирования }\end{array}$ & $1(3 \%)$ \\
\hline Гангрена тонкой кишки вследствие ишемии кишечника после бифуркационного аорто-бедренного шунтированя & $1(3 \%)$ \\
\hline $\begin{array}{l}\text { Послеоперационный перитонит вследствие несостоятельности швов анастомоза после резекции } \\
\text { тонкой кишки по поводу мезентериального тромбоза }\end{array}$ & $2(6 \%)$ \\
\hline Внутримозговое кровоизлияние вследствие симптоматической артериальной гипертензии & $2(6 \%)$ \\
\hline ТЭЛА вследствие тромбоза глубоких вен нижних конечностей & $1(3 \%)$ \\
\hline ТЭЛА вследствие множественного тромбоза артериального и венозного русла внутренних органов & $1(3 \%)$ \\
\hline Инфаркт головного мозга тромбоза общей сонной артерии & $1(3 \%)$ \\
\hline Массивная кровопотеря вследствие разрыва расслаивающей аневризмы дуги аорты & $1(3 \%)$ \\
\hline Массивная кровопотеря вследствие разрыва расслаивающей аневризмы брюшной аорты & $2(6 \%)$ \\
\hline Острая почечная недостаточность вследствие тромбоза брюшной аорты & $1(3 \%)$ \\
\hline Перитонит вследствие острого мезентериального тромбоза & $1(3 \%)$ \\
\hline Инфаркт миокарда & $2(6 \%)$ \\
\hline Рак печени & $1(3 \%)$ \\
\hline ОНМК (ишемический инсульт) & $1(3 \%)$ \\
\hline Отравление ядом & $2(6 \%)$ \\
\hline Неизвестная причина & $2(6 \%)$ \\
\hline
\end{tabular}

Примечание: ЭКС — электрокардиостимулятор; ТЭЛА — тромбоэмболия легочной артерии; ОНМК — острая недостаточность мозгового кровообращения. 


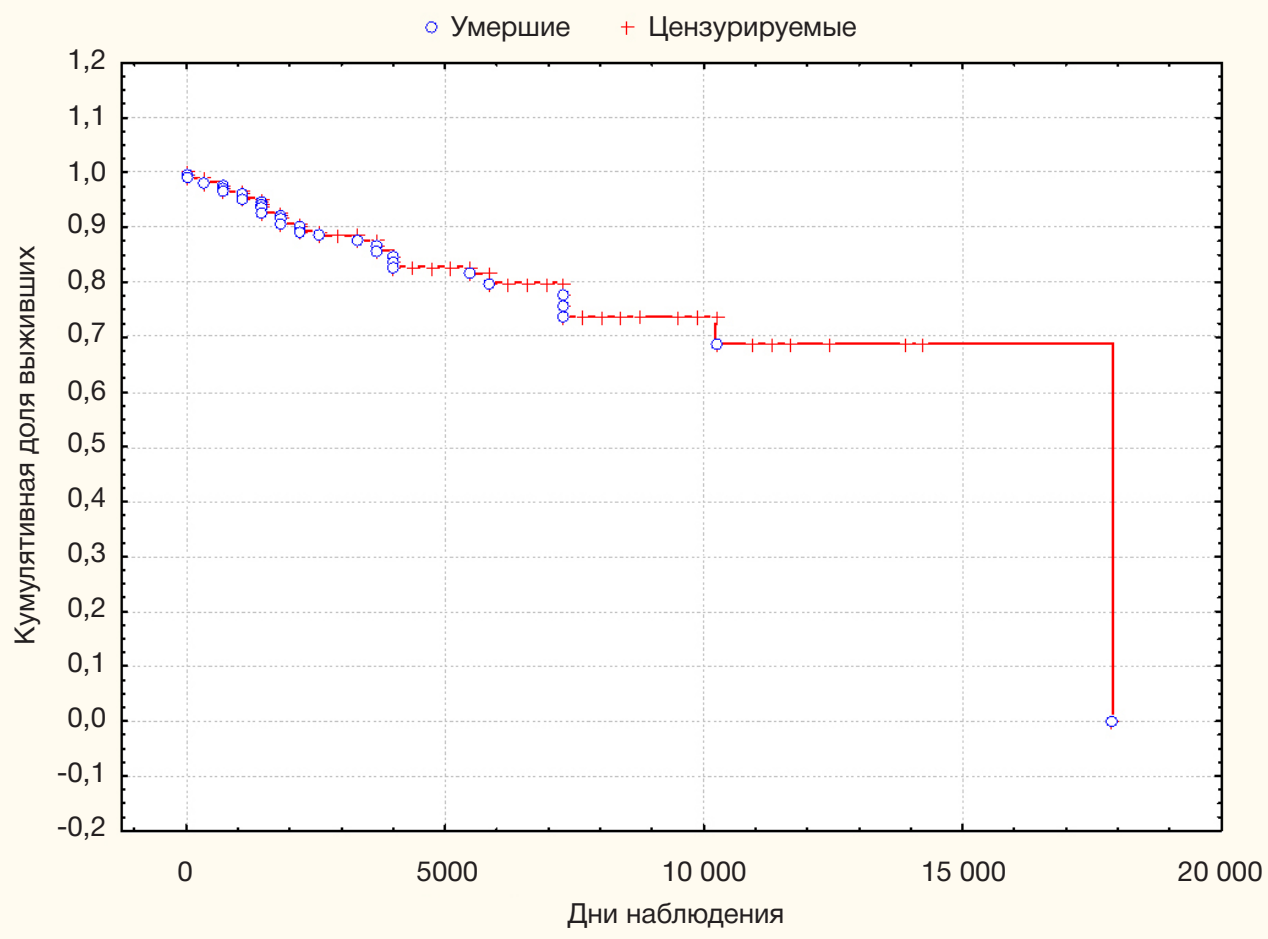

Рис. 1. Выживаемость пациентов с АТ

Таблица 7. Структура сердечно-сосудистых осложнений в когорте

\begin{tabular}{|c|c|}
\hline & Пациенты с MACE $(n=72)$ \\
\hline Инфаркт миокарда & $14(20 \%)$ \\
\hline Ишемический инсульт & $24(35 \%)$ \\
\hline Транзиторная ишемическая атака & $3(3 \%)$ \\
\hline Гемморагический инсульт & $4(6 \%)$ \\
\hline Тромбоз почечных артерий & $5(7 \%)$ \\
\hline Тромбоз плечевой артерии & $2(3 \%)$ \\
\hline Мезентериальный тромбоз & $4(6 \%)$ \\
\hline Тромбоз лучевой артерии & $1(1,4 \%)$ \\
\hline Тромбоз БЦА ствола & $1(1,4 \%)$ \\
\hline Тромбоз артерии стопы & $2(3 \%)$ \\
\hline Тромбоз подмышечной артерии & $1(1,4 \%)$ \\
\hline Тромбоз инфраренального отдела аорты & $1(1,4 \%)$ \\
\hline Тромбоз брюшной аорты & $2(3 \%)$ \\
\hline Тромбоз сонных артерий & $3(3 \%)$ \\
\hline Тромбоз подключичных артерий & $3(3 \%)$ \\
\hline Тромбоз чревного ствола & $1(1,4 \%)$ \\
\hline Разрыв аневризмы грудного отдела аорты & $2(3 \%)$ \\
\hline Разрыв аневризмы брюшного отдела аорты & $1(1,4 \%)$ \\
\hline Тромбоз аорто-бедренного шунта & $6(8 \%)$ \\
\hline Тромбоэмболия легочной артерии & $3(3 \%)$ \\
\hline Тромбоз яремной вены & $2(3 \%)$ \\
\hline Синус-тромбоз & $1(1,4 \%)$ \\
\hline Тромбоз суральных вен & $1(1,4 \%)$ \\
\hline Тромбоз малой подкожной вены & $1(1,4 \%)$ \\
\hline Тромбофлебит глубоких вен голени & $1(1,4 \%)$ \\
\hline Тромбофлебит аортовенозного шунта почечной артерии & $1(1,4 \%)$ \\
\hline
\end{tabular}


Таблица 8. Клинические проявления АТ в различных географических регионах

\begin{tabular}{|c|c|c|c|c|c|c|c|}
\hline & $\begin{array}{c}\text { Настоящее } \\
\text { исследование } \\
(n=183), \%\end{array}$ & $\begin{array}{c}\text { Италия } \\
(n=67), \% \\
{[9]}\end{array}$ & $\begin{array}{c}\text { Индия } \\
(n=106), \% \\
{[10]}\end{array}$ & $\begin{array}{c}\text { Бразилия } \\
(n=73), \% \\
{[11]}\end{array}$ & $\begin{array}{l}\text { Южная Африка } \\
(n=272), \% \\
{[12]}\end{array}$ & $\begin{array}{c}\text { Япония } \\
(n=84), \% \\
{[13]}\end{array}$ & $\begin{array}{c}\text { Россия } \\
(n=215), \% \\
{[14]}\end{array}$ \\
\hline Слабость & 47,5 & Нет данных & Нет данных & Нет данных & 10 & Нет данных & 50 \\
\hline Снижение веса & 24 & 12 & 9,4 & 28 & Нет данных & 5 & 9 \\
\hline Лихорадка & 35,5 & 39 & 16 & 26 & 10 & 20 & Нет данных \\
\hline Головная боль & 47 & 33 & 47 & 45 & Нет данных & Нет данных & 50 \\
\hline Головокружение & 22 & 27 & Нет данных & 29 & Нет данных & Нет данных & Нет данных \\
\hline $\begin{array}{l}\text { Боль, слабость, онемение } \\
\text { верхних конечностей }\end{array}$ & 49 & 52 & 59 & 58 & 12 & 54 & 50 \\
\hline $\begin{array}{l}\text { Артериальная гипертензия } \\
\text { (систолическое 140/90 мм рт. ст., } \\
\text { диастолическое } 90 \text { мм рт. ст.) }\end{array}$ & 53 & 46 & 52 & 36 & 77 & 52 & 68 \\
\hline $\begin{array}{l}\text { Асимметрия пульса } \\
\text { на верхних конечностях }\end{array}$ & 49 & 73 & 59 & 85 & 12 & 54 & 50 \\
\hline $\begin{array}{l}\text { Разность артериального давления } \\
\text { на верхних конечностях } 10 \text { мм рт. ст. }\end{array}$ & 20 & 72 & 59 & 85 & 12 & 54 & 50 \\
\hline
\end{tabular}

Таблица 9. Поражения артерий при АТ в различных географических регионах

\begin{tabular}{|c|c|c|c|c|c|c|}
\hline Артерии & $\begin{array}{c}\text { Данное исследование } \\
(n=183), \%\end{array}$ & $\begin{array}{c}\text { Китай } \\
(n=411), \% \\
{[15]}\end{array}$ & $\begin{array}{c}\text { Корея } \\
(n=20), \% \\
{[16]}\end{array}$ & $\begin{array}{c}\text { США } \\
(n=126), \% \\
{[17]}\end{array}$ & $\begin{array}{c}\text { Италия } \\
(n=104), \% \\
{[9]}\end{array}$ & $\begin{array}{c}\text { Франция } \\
(n=82), \% \\
{[18]}\end{array}$ \\
\hline Подключичные & 53 & 79.8 & 67,1 & 6,3 & 65,6 & 68,3 \\
\hline Сонные & 55 & 79,1 & 72,1 & 50,9 & 44,3 & 59,8 \\
\hline Позвоночные & 9 & 28,7 & Нет данных & 18,5 & 13 & 28,0 \\
\hline Легочные & 3 & 68,9 & 13,4 & 33,3 & Нет данных & Нет данных \\
\hline Коронарные & 17 & 35,7 & 63,3 & 22,2 & Нет данных & Нет данных \\
\hline Брыжеечные & 25 & 29,7 & 22,8 & 24,7 & 31,6 & Нет данных \\
\hline Почечные & 42 & 48,9 & 32,2 & 18,7 & 34,4 & 14,6 \\
\hline Подвздошные & 18 & 27,2 & 13,3 & 13,5 & 19,7 & 18,3 \\
\hline Восходящая аорта & 8 & 9,5 & 47,8 & 9,1 & Нет данных & Нет данных \\
\hline
\end{tabular}

здравоохранения в отношении АТ могут привести к задержке диагноза или неправильной первоначальной диагностике заболевания.

В уральской выборке 139 из 183 испытуемых составляли женщины (76\%), в то время как в других странах соотношение мужчин и женщин с АТ колебалось от $1: 2,4$ до 1: 8 в Израиле, до 6,9: 1 в Мексике и $8: 1$ в Японии [5-8]. В настоящем исследовании демографические характеристики, клиническое начало и течение заболевания соответствуют ранее опубликованным данным, сообщающим о молодом возрасте начала АТ [6-12].

Головную боль, артериальную гипертензию (определяемую как систолическое артериальное давление 140 мм рт. ст. и / или диастолическое давление 90 мм рт. ст. и выше) отмечали одинаково часто во всех исследованиях, включая и данную когорту [9-14] (табл. 8).

Наиболее распространенными локализациями поражения артериального бассейна были подключичная, сонная и почечные артерии. Наиболее частым видом поражения был стеноз. Наиболее частым типом АТ был тип V (43\%). Также обнаружено, что поражение сонных артерий и подключичной артерии было одинаково частым во всех исследованиях, включая это. В нашей когорте, как и в других публикациях, отмечено крайне редкое вовлечение позвоночных, легочных, подвздошных артерий. Описан высокий процент поражения восходящей аорты и коронарных артерий у жителей Кореи [9,15-18] (табл. 9).

Согласно данным исследователей Российской Федерации, поражение брахиоцефальных артерий зарегистрировано в 85\% случаев, почечной артерии - в 23\% случаев [19, 20] (табл. 10).

Наиболее частым типом поражения крупных сосудов во всех исследованиях, кроме сербского, был тип $\mathrm{V}$, a тип III был отмечен как наиболее редкий. Для сербской выборки была характерна высокая частота поражений типа I и типа Ila, в то время как в корейской популяции наиболее распространен тип Ilb, а в Индии и Бразилии относительно высока выявляемость поражений IV типа. Вклад в различные клинические проявления АТ могут вносить как генетические, так и экологические факторы (табл. 11) [15-17, 21-24].

Выживаемость пациентов в нашей когорте была схожа с данными предыдущих публикаций [17, 25-27]. Существуют также разные данные с пятилетней и 10-летней 
Таблица 10. Поражение артерий при АТ в российской популяции

\begin{tabular}{|c|c|c|c|}
\hline Артерии & Настоящее исследования $(n=183)$ & Центральные регионы России [19] & (Североевропейские регионы России) [20] \\
\hline Подключичная & 55 & \multirow{3}{*}{$85 \%$} & Нет данных \\
\hline Сонная & 53 & & Нет данных \\
\hline Позвоночная & 9 & & Нет данных \\
\hline Легочная & 3 & Нет данных & Нет данных \\
\hline Коронарная & 17 & Нет данных & Нет данных \\
\hline Брыжеечная & 25 & Нет данных & Нет данных \\
\hline Почечная & 42 & Нет данных & $23 \%$ \\
\hline Подвздошная & 18 & Нет данных & Нет данных \\
\hline Восходящая аорта & 5 & Нет данных & Нет данных \\
\hline
\end{tabular}

Таблица 11. Ангиографические характеристики АТ в различных регионах мира

\begin{tabular}{|l|c|c|c|c|c|c|c|c|}
\hline & Настоящее исследование & Китай [15] & Корея [16] & США [17] & Индия [21] & Мексика [22] & Сербия [23] & Бразилия [24] \\
\hline Тип I, \% & 33 & 22,1 & 11,1 & 20 & 6.9 & 19 & 50 & 11.9 \\
\hline Тип IIa, \% & 5 & 3,9 & 8,6 & 6 & 1 & 3 & 19 & 6 \\
\hline Тип IIb, \% & 0,5 & 3,9 & 14,1 & 7 & 5,9 & 4 & 0 & 1 \\
\hline Тип III, \% & 2 & 2,9 & 4,0 & 5 & 2,9 & 4 & 0 & 9 \\
\hline Тип IV, \% & 17 & 6,3 & 7,6 & 5 & 28,4 & 2 & 0 & 27 \\
\hline Тип V, \% & 43 & 60,8 & 54,5 & 57 & 54,9 & 69 & 31 & 18 \\
\hline
\end{tabular}

выживаемостью (69 и 36\%) [28]. Пятилетняя выживаемость арабского населения составила только 50\% [29]. Между тем японские пациенты показали 100\%-ю пятилетнюю выживаемость [30].

Для определения распространенности заболевания среди различных этнических групп крайне необходимо ввести общенациональный реестр АТ.

Общенациональный реестр АТ поможет лучше описать представление АТ и клиническое течение, что повысит осведомленность медицинских специалистов об этом заболевании и своевременную его диагностику. Фактическая распространенность АТ может быть значительно выше, чем предполагается из данных литературы. Своевременные диагностика и терапия могут улучшить исходы пациентов с АТ.

Основным ограничением данного исследования является его ретроспективный характер. Ретроспективный характер исследования обусловливает различия в объеме и перечне обследований пациентов в разные годы, а также затрудняет соответствующую интерпретацию данных.

\section{ВЫВОДЫ}

Клиническая картина АТ разнообразна. Своевременная диагностика может быть затруднена на «стадии сохранного пульса» из-за формирования коллатерального кровообращения, когда кроме общевоспалительной симптоматики не наблюдаются симптомы, характерные для поражения артерий. Пациенты с АТ должны быть предупреждены о высоком риске сердечно-сосудистых осложнений и контролировать артериальное давление, показатели липидного спектра, свертываемости крови. Своевременная хирургическая коррекция гемодинамически значимых стенозов, окклюзий и тромбозов пораженных сосудов позволяет оптимизировать лечение артериальной гипертензии, ликвидировать симптомы ишемии конечностей и предупредить развитие новых сосудистых осложнений. У большинства пациентов наблюдался генерализованный $\vee$ тип поражения артерий. Достаточно высокая выживаемость при AT может быть обусловлена молодым возрастом пациентов и развитием коллатерального кровообращения.

\section{Литература}

1. Насонов Е. Л. Ревматология: российские клинические рекомендации. М.: ГЕОТАР-Медиа, 2010; 331 с.

2. Волосников Д. К., Глазырина Г. А., Серебрякова Е. Н. Неспецифический аортоартериит (артериит Такаясу) у детей и подростков: обзор литературы и описание случая. Трудный пациент. 2015; 1 (13): 36-9.

3. Arend W, Michel B, Bloch D, et al. The American College of Rheumatology 1990 criteria for the classification of Takayasu arteritis. Arthritis Rheum. 1990; (33): 1129-34.

4. Moriwaki R, Noda M, Yajima M, et al. Clinical manifestations of Takayasu arteritis in India and Japan new classification of angiographic findings. Angiology. 1997; (48): 369-79.

5. Asri A, Tazi-Mezalek Z, Aouni M, et al. Takayasu's disease in Morocco. Report of 47 cases. Rev Med Interne. 2002; (23): 9-20.

6. Ishikawa K, Maetani S. Long-term outcome for 120 Japanese patients with Takayasu's disease. Clinical and statistical analyses of related prognostic factors. Circulation. 1994; (90): 1855-60.

7. Toshihiko N. Current status of large and small vessel vasculitis in Japan. Int J Cardiol. 1996; (54): 91-8.

8. Zheng DY, Liu LS, Fan DJ. Clinical studies in 500 patients with aortoarteritis. Chin Med J. 1990; (103): 536-40.

9. Vanoli M, Bacchiani G, Origgi L, et al. Takayasu's arteritis: a changing disease. J Nephrol. 2001; (14): 497-505.

10. Jain S, Kumari S, Ganguly N, et al. Current status of Takayasu arteritis in India. Int J Cardiol. 1996; (54): 111-6.

11. Sato EL, Hatta FS, Levy-Neto M, et al. Demographic, clinical, and angiographic data of patients with Takayasu arteritis in Brazil. Int J Cardiol. 1998; (66): 67-70. 
12. Mwipatayi B, Jeffeiy P. Takayasu arteritis: clinical features and management: report of 272 cases. ANZ J Surg. 2005; (75): 110-7.

13. Nakao K, Ikeda M, et al. Takayasu's arteritis: Clinical Report of Eighty-four Cases and Immunological Studies of Seven Cases. Circulation. 1967; (35): 1141-55.

14. Арабидзе Г. Г., Абугова С. П., Матвеева Л. С. Клинические аспекты болезни Такаясу (215 наблюдений). Тер. архив. 1980; (5): 124-9.

15. Jing Li, Fei Sun, et al. The clinical characteristics of Chinese TAayasu's arteritis patients: a retrospective study of 411 patients over 24 years. Arthritis Res Ther. 2017; (19): 107. DOI: 10.1186/ s13075-017-1307-Z

16. Lee GY, Jang SY, Ko SM, et al. Cardiovascular manifestations of TAayasu arteritis and their relationship to the disease activity: analysis of 204 Korean patients at a single center. Int J Cardiol. 2012; 159 (1): 14-20.

17. Schmidt J, Kermani TA, Bacani AK, et al. Diagnostic features, treatment, and outcomes of Takayasu arteritis in a US cohort of 126 patients. Mayo Clin Proc. 2013; 88 (2): 821-30.

18. Arnaud L, Haroche J, Toledano D, et al. Cluster analysis of arterial involvement in Takayasu arteritis reveals symmetric extension of the lesions in paired arterial beds. Arthritis Rheum. 2011; 63 (4): 1136-40.

19. Покровский А. В., Зотиков А. Е., Юдин В. И. Неспецифический аортоартериит (болезнь Такаясу). М.: ИРСИСъ, 2002.

20. Чихладзе Н. М. Артериальная гипертензия у больных с неспецисическим аортоартериитом. Системные гипертензии. 2018; 15 (2): 43-8.

21. Moriwaki R, Noda M, Yajima $M$, et al. Clinical manifestations of Takayasu arteritis in India and Japan - new classification of angiographic findings. Angiology. 1997; 48 (5): 369-79.

22. Soto ME, Espinola N, Flores-Suarez LF, et al. Takayasu arteritis: clinical features in 110 Mexican Mestizo patients and cardiovascular impact on survival and prognosis. Clin Exp Rheumatol. 2008; 26 (3 Suppl 49): 9-15.

23. Petrovic-Rackov L, Pejnovic N, Jevtic M, et al. Longitudina study of 16 patients with Takayasu's arteritis: clinical features and therapeutic management. Clin Rheumatol. 2009 Feb; 28 (2): 179-85. DOI: 10.1007/s10067-008-1009-7.

24. Clemente Maria, et al. Brazilian multicenter study of 71 patients with juvenile-onset TAayasu's arteritis: clinical and angiographic features. Rev Brasil Reumatol. 2016 Mar; 56 (2): 145-51.

25. Phillip R, Luqmani R. Mortality in systemic vasculitis: a systemic review. Clin Exp Rheumatol. 2008; 26 (5): 94-104.

26. Balakrishnan KG, Subramanyan R, Joy J. Natural history of aortoarteritis (Takayasu's disease). Circulation. 1989; 80 (3): 429-37.

27. Hall S, Barr W, Lie JT, Stanson AW, Kazmier FJ, Hunder GG. Takayasu arteritis. A study of 32 North American patients. Medicine (Baltimore). 1985; 64 (2): 89-99.

28. Park MC, Lee SW, Park YB, Chung NS. Clinical characteristics and outcomes of Takayasus arteritis: analysis of 108 patients using standardized criteria for diagnosis, activity assessment and angiographic classification. Lee Scand J Rheumatol. 2005; 34 (4): 284-92.

29. Mustafa K. Takayasu's arteritis in Arabs. Clin Rheumatol. 2014 Dec; 33 (12): 1777-83. DOI: 10.1007/s10067-014-2633-z.

30. Ishihara T, Haraguchi G, Kamiishi T, Tezuka D, Inagaki H, Isobe M. Sensitive assessment of activity of Takayasu's arteritis by pentraxin3, a new biomarker. J Am Coll Cardiol. 2011; 57 (16): $1712-3$

\section{References}

1. Nasonov EL, Nasonova VA. Rheumatology. National guidelines. Moscow, 2010; 539-67.

2. Volosnyakov D, Glazyrina G, Serebryakova E, et al. Nonspecific aortoarteritis (Takayasu arteritis) in children and adolescents: literature review and clinical case. Difficult patient. 2015; 1 (13): 36-9.

3. Arend W, Michel B, Bloch D, et al. The American College of Rheumatology 1990 criteria for the classification of Takayasu arteritis. Arthritis Rheum. 1990; (33): 1129-34.

4. Moriwaki R, Noda M, Yajima M, et al. Clinical manifestations of Takayasu arteritis in India and Japan new classification of angiographic findings. Angiology. 1997; (48): 369-79.

5. Asri A, Tazi-Mezalek Z, Aouni M, et al. Takayasu's disease in Morocco. Report of 47 cases. Rev Med Interne. 2002; (23): 9-20.

6. Ishikawa K, Maetani S. Long-term outcome for 120 Japanese patients with Takayasu's disease. Clinical and statistical analyses of related prognostic factors. Circulation. 1994; (90): 1855-60.

7. Toshihiko N. Current status of large and small vessel vasculitis in Japan. Int J Cardiol. 1996; (54): 91-8.

8. Zheng DY, Liu LS, Fan DJ. Clinical studies in 500 patients with aortoarteritis. Chin Med J. 1990; (103): 536-40.

9. Vanoli M, Bacchiani G, Origgi L, et al. Takayasu's arteritis: a changing disease. J Nephrol. 2001; (14): 497-505.

10. Jain S, Kumari S, Ganguly N, et al. Current status of Takayasu arteritis in India. Int J Cardiol. 1996; (54): 111-6.

11. Sato EL, Hatta FS, Levy-Neto M, et al. Demographic, clinical, and angiographic data of patients with Takayasu arteritis in Brazil. Int $J$ Cardiol. 1998; (66): 67-70

12. Mwipatayi B, Jeffeiy P. Takayasu arteritis: clinical features and management: report of 272 cases. ANZ J Surg. 2005; (75): 110-7.

13. Nakao K, Ikeda M, et al. Takayasu's arteritis: Clinical Report of Eighty-four Cases and Immunological Studies of Seven Cases. Circulation. 1967; (35): 1141-55.

14. Arabidze G, Abugova SP, et al. Clinical aspects of Takayasu syndrome (215 cases). Ter Arkh. 1980; 52 (5): 124-9.

15. Jing Li, Fei Sun, et al. The clinical characteristics of Chinese TAayasu's arteritis patients: a retrospective study of 411 patients

over 24 years. Arthritis Res Ther. 2017; (19): 107. DOI: 10.1186/ s13075-017-1307-z.

16. Lee GY, Jang SY, Ko SM, et al. Cardiovascular manifestations of TAayasu arteritis and their relationship to the disease activity: analysis of 204 Korean patients at a single center. Int J Cardiol. 2012; 159 (1): 14-20.

17. Schmidt J, Kermani TA, Bacani AK, et al. Diagnostic features, treatment, and outcomes of Takayasu arteritis in a US cohort of 126 patients. Mayo Clin Proc. 2013; 88 (2): 821-30.

18. Arnaud L, Haroche J, Toledano D, et al. Cluster analysis of arterial involvement in Takayasu arteritis reveals symmetric extension of the lesions in paired arterial beds. Arthritis Rheum. 2011; 63 (4): 1136-40.

19. Pokrovskij AV, Zotikov AE, Yudin VI. Nespecificheskij aortoarteriit (bolezn' Takayasu). M.: IRIS, 2002.

20. Chikhladze NM. Arterial hypertension in patients with non-specific aortoarteritis. Systemic Hypertension. 2018; 15 (2): 43-48. DOI: 10.26442/2075-082X_2018.2.43-48.

21. Moriwaki R, Noda $M$, Yajima $M$, et al. Clinical manifestations of Takayasu arteritis in India and Japan-new classification of angiographic findings. Angiology. 1997; 48 (5): 369-79.

22. Soto ME, Espinola N, Flores-Suarez LF, et al. Takayasu arteritis: clinical features in 110 Mexican Mestizo patients and cardiovascular impact on survival and prognosis. Clin Exp Rheumatol. 2008; 26 (3 Suppl 49): 9-15.

23. Petrovic-Rackov L, Pejnovic N, Jevtic M, et al. Longitudinal study of 16 patients with Takayasu's arteritis: clinical features and therapeutic management. Clin Rheumatol. 2009 Feb; 28 (2): 179-85. DOI: 10.1007/s10067-008-1009-7.

24. Clemente Maria, et al. Brazilian multicenter study of 71 patients with juvenile-onset TAayasu's arteritis: clinical and angiographic features. Rev Brasil Reumatol. 2016 Mar; 56 (2): 145-51.

25. Phillip R, Lugmani R. Mortality in systemic vasculitis: a systemic review. Clin Exp Rheumatol. 2008; 26 (5): 94-104.

26. Balakrishnan KG, Subramanyan R, Joy J. Natural history of aortoarteritis (Takayasu's disease). Circulation. 1989; 80 (3): 429-37.

27. Hall S, Barr W, Lie JT, Stanson AW, Kazmier FJ, Hunder GG. 


\section{ORIGINAL RESEARCH I CARDIOLOGY}

Takayasu arteritis. A study of 32 North American patients. Medicine (Baltimore). 1985; 64 (2): 89-99.

28. Park MC, Lee SW, Park YB, Chung NS. Clinical characteristics and outcomes of Takayasus arteritis: analysis of 108 patients using standardized criteria for diagnosis, activity assessment and angiographic classification. Lee Scand J Rheumatol. 2005; 34 (4): 284-92.
29. Mustafa K. Takayasu's arteritis in Arabs. Clin Rheumatol. 2014 Dec; 33 (12): 1777-83. DOI: 10.1007/s10067-014-2633-z.

30. Ishihara T, Haraguchi G, Kamiishi T, Tezuka D, Inagaki H, Isobe M. Sensitive assessment of activity of Takayasu's arteritis by pentraxin3, a new biomarker. J Am Coll Cardiol. 2011; 57 (16): 1712-3. 